\title{
O Uso De Smartphone E Seu Impacto No Cotidiano Da Vida Dos Acadêmicos
}

\section{The use of Smartphones and their Impact on the Daily Lives of Academics}

Rafael Souza Silva1, Eduardo Soares Bílio², Kathleen Thiara dos Reis Pinto ${ }^{3}$, Leidiany Souza Silva ${ }^{4}$, Rogério Carvalho de Figueiredo ${ }^{5}$

\section{RESUMO}

A globalização, assistida pelo advento das novas tecnologias e pelo o avanço da internet, trouxeram consigo uma nova configuração da sociedade. Numa época em que a tecnologia se altera com velocidade constante. O computador e a tecnologia de internet que foi inicialmente projetado para uso em áreas limitadas, tornou-se uma ferramenta que é usada por quase todas as pessoas na sociedade atual. Assim, objetivou-se compreender de que forma o uso indiscriminado dos Smarthphones pode interferir no desempenho acadêmico, por meio da ampliação da discussão sobre a temática. O estudo é uma pesquisa exploratória, analítica, observacional, transversal de campo com análise quantitativa que contou com a participação de 152 acadêmicos da área da saúde de uma instituição privada da região norte do Estado do Tocantins. Evidentemente, a temática apresentou uma evolução significativa nos últimos anos, é notório que a internet trouxe facilidades para o acesso à informação, porém é possível perceber que este acesso de maneira desorganizada prejudica, em diversas áreas do cotidiano acadêmico, já que apresenta utilização por períodos acima do necessário, mostrando equívocos no manuseio, sendo majoritariamente utilizado para acessos em aplicativos de chats de bate papo, o que acaba, de algum modo, tirando o foco do aprendizado.

Palavras-chave: Uso indiscriminado de celular; Desempenho acadêmico; Impacto

\section{ABSTRACT}

Globalization, assisted by the advent of new technologies and the advancement of the internet, brought with it a new configuration of society. At a time when technology changes with constant speed. The computer and internet technology that was initially designed for use in limited areas, has become a tool that is used by almost everyone in today's society. Thus, the objective was to understand how the indiscriminate use of Smarthphones can interfere with academic performance, by expanding the discussion on the theme. The study is an exploratory, analytical, observational, cross-sectional field study with quantitative analysis that included the participation of 152 academics in the health field of a private institution in the northern region of the State of Tocantins. Evidently, the theme has evolved significantly in recent years, it is notorious that the internet has brought facilities for access to information, but it is possible to perceive that this access in a disorganized way harms, in several areas of academic life, since it has been used for periods above what is necessary, showing mistakes in handling, being mostly used for accessing chat chat applications, which ends up, in some way, taking the focus away from learning.

Keywords: indiscriminate use of mobile phones; Academic achievement; Impact
Enfermeiro Especialista e docente em Faculdade de Colinas; Docente em Instituto Educacional de Santa Catarina Faculdade de Guaraí, IESC/FAG. E-mail: rafael.unirg@gmail.com

2 Graduanda do curso de Enfermagem.

3 Graduanda do curso de Enfermagem.

Enfermeira. Esp. Docente do Curso de Enfermagem.

Enfermeiro. M.e Docente do Curso de Enfermagem. 


\section{INTRODUCCAOA}

A globalização, assistida pelo advento das novas tecnologias e pelo o avanço da internet trouxeram consigo uma nova configuração da sociedade. (VEGA, CORREA \& SÁNCHEZ, 2015).

Numa época em que a tecnologia se altera com velocidade constante. O computador e a tecnologia de internet que foi inicialmente projetado para uso em áreas limitadas, tornou-se uma ferramenta que é usada por quase todas as pessoas na sociedade atual. É comum perceber o uso da rede via celular (SILVA, LOPES \& LIMA (2017).

O primeiro telefone celular foi fabricado no ano de 1973 e pesando mais de um $\mathrm{kg}$ e com menos de 20 minutos de resistência da bateria foi bastante impraticável em comparação com os telefones contemporâneos. Com o passar do tempo, estes telefones passaram por grandes transformações tanto que é considerado e utilizado como um computador de bolso (AKIN; ALTUNDAG; TURAN, 2014).

A tecnologia mais recente é chamada de Smarthphone (telefones inteligentes), que proporciona as pessoas funções como acesso à internet, mídias sociais (Whatsapp, Facebook, Twitter, Instagran, Skype...), jogos online, dentre outros (KWON et al., 2013).

INTERNATIONAL DATA CORPORATION - IDC (2016) sugere que os smartphones (telefones inteligentes) ganharam um lugar especial na vida de seus consumidores, fazendo parte de suas rotinas diárias, pois são aparelhos pequenos, que muitas vezes cabem na palma da mão e dispõe de vários recursos, conquistando desde o público infantil até o público idoso.

Klauer et al., (2014) descrevem que as vantagens trazidas pela modernidade nos dispositivos móveis trouxeram enorme conveniência para a sociedade moderna, mas considerando que os smartphones estão compartilhando a maioria dos aspectos da Internet, o vício dos smartphones é altamente susceptível a causar problemas biopsicossociais. Visto isto, lembra-se das constantes campanhas que alertam para o uso do dispositivo enquanto se dirige, com pesquisas que comprovam o aumento a situações de riscos (colisões e outros acidentes de trânsito).

O uso indiscriminado de Smarthphone introduz o indivíduo ao espaço virtual, fazendo com que diminua suas atividades sociais e familiares, gerando, consequentemente, certo isolamento, além de distúrbios que passam pela dificuldade de controlar o tempo de uso do equipamento, problemas ocupacionais, alteração substancial 
do relógio biológico humano e problemas relacionados à ansiedade, à irritação, à agitação, à tensão e à depressão (BARROS; RICHTER, 2013).

Do mesmo modo, a dependência comportamental exerce um papel semelhante a dependência química, é além disso marcada pela existência de sintomas físicos e psicológicos significativos, podendo ocorrer explosões de forte emoção, sentimento de perda, separação, frustração, intranquilidade, sentimento de que falta alguma coisa ou até mesmo expressões físicas de raiva e manipulação, podendo afetar os sistemas biológicos aumentando a produção de radicais livres, danificando células sadias do corpo e mudando os sistemas de defesa antioxidante de tecidos humanos, podendo levar assim ao estresse oxidativo (GREENFIELD, 2011).

É de conhecimento geral que a tecnologia móvel vem ganhando cada vez mais espaço no cotidiano das pessoas, dessa forma, verifica-se uma crescente utilização por parte de jovens e adultos no ensino superior.

A Enfermagem, sendo entendida como uma profissão também voltada à promoção de saúde, precisa discutir o tema, já que é evidente a influência do uso indiscriminado dos telefones inteligentes na vida das pessoas, tornando a abordagem do assunto, pertinente ao crescimento profissional dentro da ótica de se promover saúde.

Dessa forma, o estudo permite discutir e aperfeiçoar o nível de informação do tema acerca da utilização de dispositivos móveis, levando em consideração ainda que estudos abrangentes voltados ao ensino superior são escassos, tornando-se assim relevante a profissão e a vida das pessoas.

Devido à importância do assunto pautado, viu-se necessário buscar fatores que se enquadram em tal problemática, assim o estudo surge guiado pelo questionamento: De que forma o uso excessivo de smartphone pode impactar no cotidiano da vida dos acadêmicos?

Portanto, o objetivo foi compreender como o uso indiscriminado dos Smarthphones pode interferir no desempenho acadêmico, por meio da ampliação da discussão sobre a temática, apurando seus prováveis efeitos sob o âmbito familiar, aspectos de saúde e processo de ensino-aprendizagem de jovens e adultos da faixa etária acima de 18 anos. 


\section{MATERIAIS E METODOS}

O presente estudo é uma pesquisa de campo exploratória, analítica, observacional, transversal com análise quantitativa (CERVO, BERVIAN, 2002). Foi realizada em instituição privada de ensino superior, num Município do interior do Estado do Tocantins.

Para composição da amostra, foram convidados para a pesquisa, acadêmicos com idade acima de 18 anos, que estiverem presentes na Instituição de Ensino Superior, no período letivo compreendido como primeiro semestre do ano de 2019, em horário entre 13:00 as $17: 00$ e das 19:00 as $22: 30$ horas, e se dispuserem a participar da entrevista assinando o Termo de Consentimento Livre e Esclarecido (TCLE). O total de pessoas convidadas foi 204 participantes, porém após enquadramento de critérios de inclusão, participaram 152 estudantes.

A amostra foi composta por estudantes de ambos os sexos; com idade a partir dos 18 anos; que frequentem instituição de Ensino superior privada, presentes no segundo semestre do ano de 2019 e aceitaram fazer parte do estudo assinando o TCLE, totalizando 152 participantes.

Foram excluídos da pesquisa, acadêmicos que declararam não querer participar; os que não eram da categoria estudante; os que tenham idade abaixo de 18 anos; ou recusaram fazer parte do estudo não assinando o TCLE, que totalizou 52 convidados.

Dessa forma, após os pesquisadores relatarem aos pesquisados o seu esclarecimento quanto aos objetivos da pesquisa e os mesmos assinaram o TCLE, a coleta de dados se procedeu, por meio de uma entrevista utilizando questionário, que avaliou 04 (quatro) quesitos: Perfil do acadêmico; Utilização dos smartphones ou tablets?; Possíveis problemas provenientes pelo uso dos smartphones ou tablets e da Internet; Outras questões acerca dos smartphones e/ou tablets; onde os próprios pesquisadores preencheram, em local reservado e sem interferência externa, o instrumento de pesquisa juntamente com o pesquisado.

O estudo seguiu a luz da resolução 466/12 do Conselho Nacional de Saúde, que define as diretrizes e normas reguladoras das pesquisas envolvendo seres humanos, sendo submetido para aprovação junto ao Comitê de Ética e Pesquisa do CEP - Comitê de Ética e Pesquisa da Faculdade de Ciências do Tocantins - FACIT, através da Plataforma Brasil com o CAAE 13307819.0.0000.8408, obtendo Parecer Favorável nํㅡㄴ 3.519.746. 
O instrumento de pesquisa adotado foi o questionário, com versão brasileira criada KOBS (2017), sendo adaptada para o estudo. É um instrumento auto administrado que considera 04 (quatro) aspectos. As questões foram dispostas nesta forma: Perfil do acadêmico (06 questões); Utilização dos smartphones ou tablets? (11 questões); possíveis problemas provenientes pelo uso dos smartphones ou tablets e da Internet (07 questões); outras questões acerca dos smartphones e/ou tablets (03 questões); possuem cinco alternativas de resposta.

Os pesquisadores procederam à entrevista dos estudantes, individualmente e registraram os dados manualmente em impresso do instrumento próprio e por meio de computador, conforme referido anteriormente no projeto.

Ao final da coleta dos dados os participantes foram orientados individualmente sobre os agravos advindos do uso excessivo dos Smarthphones, tiveram suas dúvidas esclarecidas pelos pesquisadores, com enfoque na prevenção e controle para evitar ou minimizar as incapacidades já instaladas.

Os dados obtidos foram apresentados descritivamente, em forma de gráficos e em tabelas contendo frequências absolutas (n) e relativas (\%). O nível de significância e o processamento dos dados adotados foi de $95 \%$ com margem de erro de $5 \%$.

\section{RESULTADOS E DISCUSSÕES}

Os telefones inteligentes encontram-se entre os principais temas discutidos atualmente, tanto no meio organizacional quanto no acadêmico. A grande demanda dessa tecnologia levantou-se uma série de questões relativas à sua criação, escolha, adaptação e vantagens de utilização, sobretudo no âmbito da saúde (KOBS, 2017).

Com base neste método, foi tabulado o perfil de uso deste equipamento através do módulo I do questionário, sendo pesquisado um total de 152 acadêmicos, onde 116 (76\%) dos participantes da pesquisa eram mulheres e apenas 36 (24\%) eram do sexo masculino, cursavam os cursos de psicologia (33 participantes), Enfermagem (82 participantes) e Direito (37 Participantes) que cursavam de acordo com os períodos distribuídos logo abaixo no gráfico 01. 


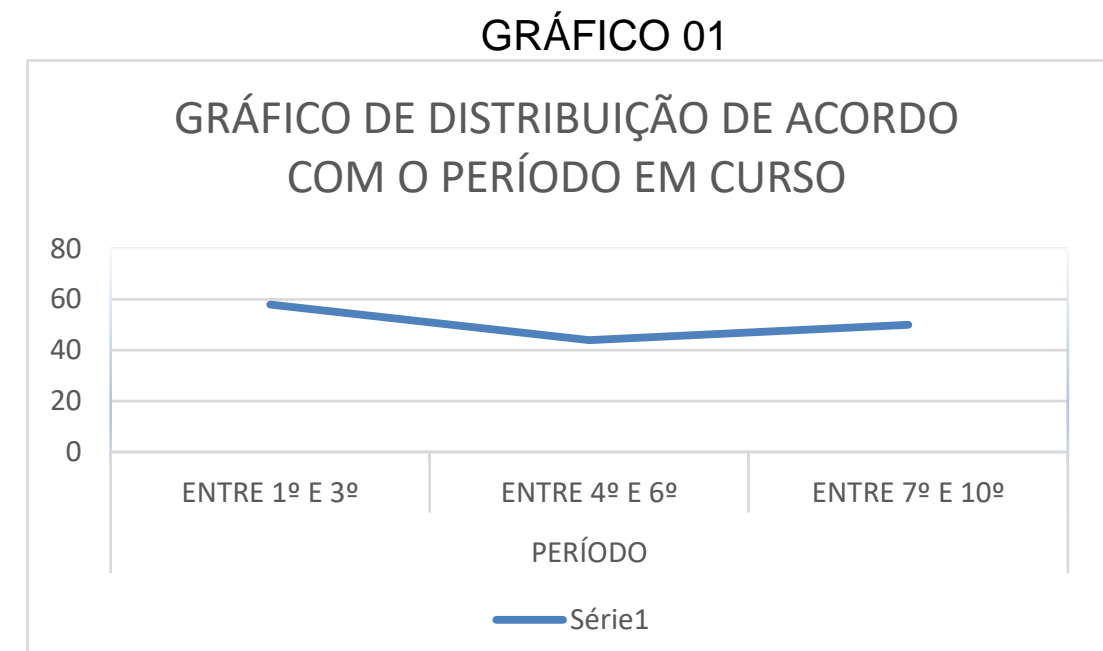

Fonte: Dados coletados entre os acadêmicos de uma IES particular no primeiro semestre do ano de 2019.

Contudo, esta tecnologia possui um enorme potencial, para aplicação na área da saúde, aplicativos para smartphones estão sendo desenvolvidos como uma forma complementar de qualificar tanto em monitoramento da saúde quanto para diagnósticos. Conseguindo auxiliar também em abordagens terapêuticas e prescrições de medicamentos (MINISTÉRIO DA SAÚDE, 2018).

Resende (2016) afirma que os serviços de tecnologia móveis destinados a saúde só contribuem, por exemplo, na recepção em pronto-socorro, encurtando as filas de espera, no processamento de dados clínicos e até o completo serviço móvel com laptops do tipo "tablet" associados a Personal Assistant Digital (PDAs) e a celulares).

Concordando com a ideia supracitada e utilizando os resultados do estudo, fica o questionamento sobre o mal uso. Dentro da academia o uso está distribuído conforme gráfico 02 abaixo, evidenciando que a maioria tem frequência de uso, porém a parte majoritária de participantes também refere que os faz perder tempo e ainda atrapalha a estudar.

GRÁFICO 02 - Hábitos e Frequência de Uso




Lima e Pereira (2015), mostram que existe uma aproximação do profissional de saúde e o paciente, desfazendo obstáculos de comunicação e por ser, de maior parte, de uso comum acaba instituindo uma relação imediata com uma área tecnologicamente aberta aos usuários.

Por outro lado, o uso indiscriminado pode submeter o indivíduo a efeitos negativos, tais como os biomecânicos, vale destacar que os mais comuns são: elevada repetição do movimento, vibração, uso de ferramentas manuais, forças elevadas e posturas inadequadas ocasionando sintomas como desconforto, algias, sensação de peso, paresias e parestesias. (ROCHA, 2018).

O gráfico 03 mostra o que o acadêmico mais acessa via celular.

\section{GRÁFICO 03}

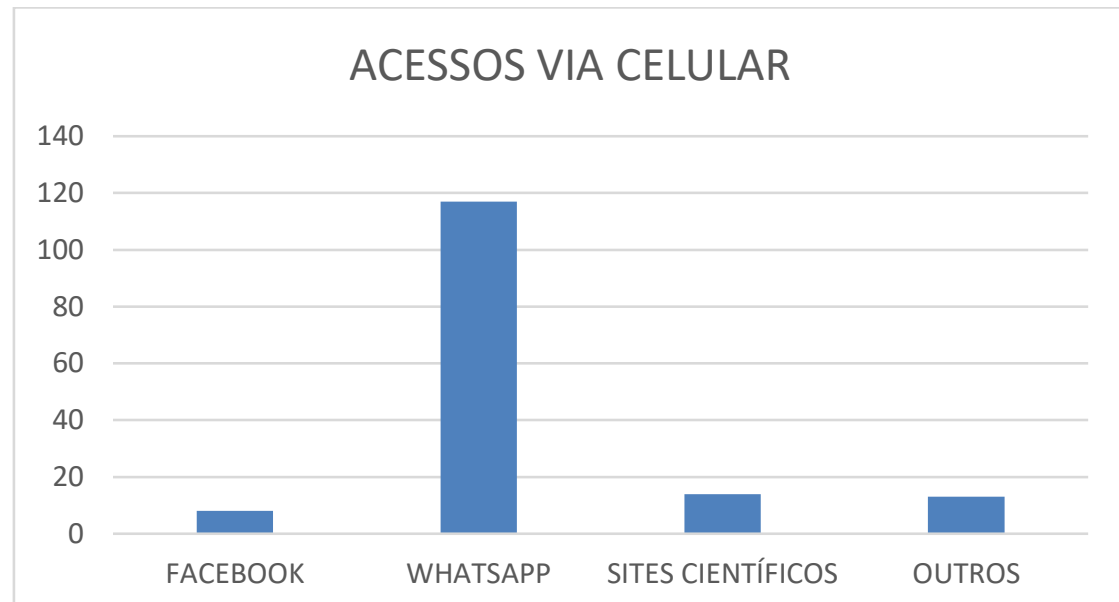

Fonte: Dados coletados entre os acadêmicos de uma IES particular no primeiro semestre do ano de 2019.

A informação acima permite a constatação que a maior taxa de uso, se dá em fontes que não tem o objetivo de busca de informações científicas, o que pode ocasionar ao acadêmico perca de tempo e ainda ocupar a mente com informações irrelevantes a seu aprendizado e crescimento profissional.

O gráfico 04 mostra que a maioria utiliza os dispositivos por um grande período do dia e se ainda considerarmos que a instituição pesquisada oferta cursos apenas no período noturno, o período de manuseio se torna um problema ainda mais grave, já que um acadêmico precisa de uma boa noite de sono e em sua rotina, comumente, ainda trabalha durante o dia. 
GRÁFICO 04 - Tempo de Uso do Celular em Horas

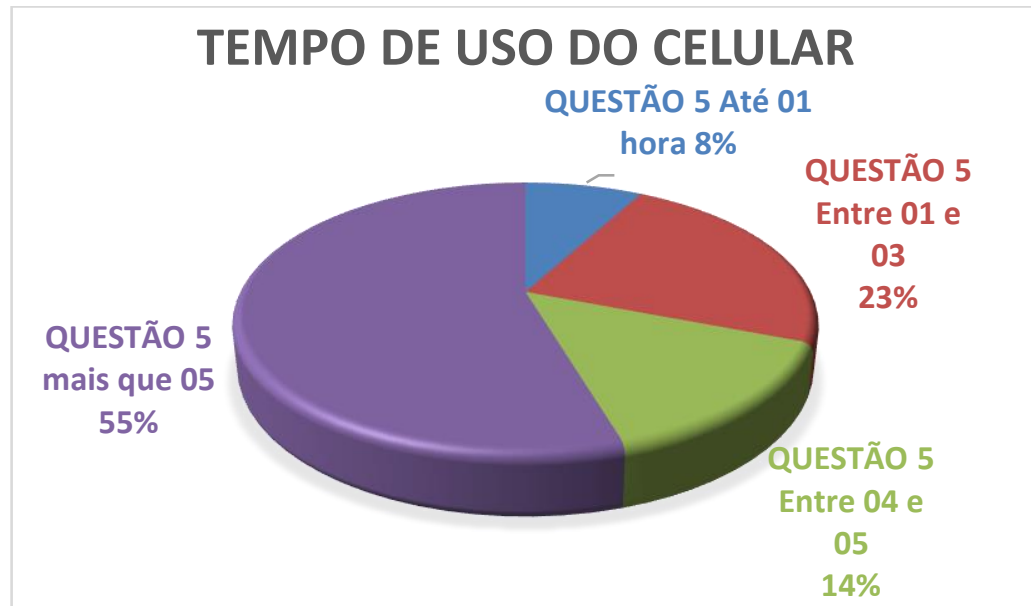

Fonte: Dados coletados entre os acadêmicos de uma IES particular no primeiro semestre do ano de 2019.

Assim, a falta de controle e domínio para com o uso das tecnologias, traz consigo complicações tanto físicas como psicológicas, que surgem de forma progressiva gerando a interferência nas relações, principalmente familiares (MELO et al, 2018).

Para Kim, Kim e Jee, (2015), o uso intensivo de smartphone pode diminuir a quantidade das atividades físicas (AF), e causar lesões nos usuários bem como insônia, distanciamento familiar e baixo rendimento escolar por exemplo.

Para os autores supracitados, a falta de atividades físicas básicas como o simples ato de caminhar leva ao sedentarismo, repercutindo num aumento da massa de gordura e uma redução da massa muscular associada a efeitos adversos para a saúde.

Carvalho, et al. (2013) explica bem o gráfico 05 (Citado abaixo) mostrando que uso ininterrupto da internet a conectividade 24 horas, 0 acesso as mídias sociais principalmente no período noturno podem alterar o padrão de sono, ocasionando quadros de insônia, mudanças de comportamento e nos relacionamentos sociais. As poucas horas de sono afeta diretamente na qualidade de vida das pessoas diminuindo a longevidade. 


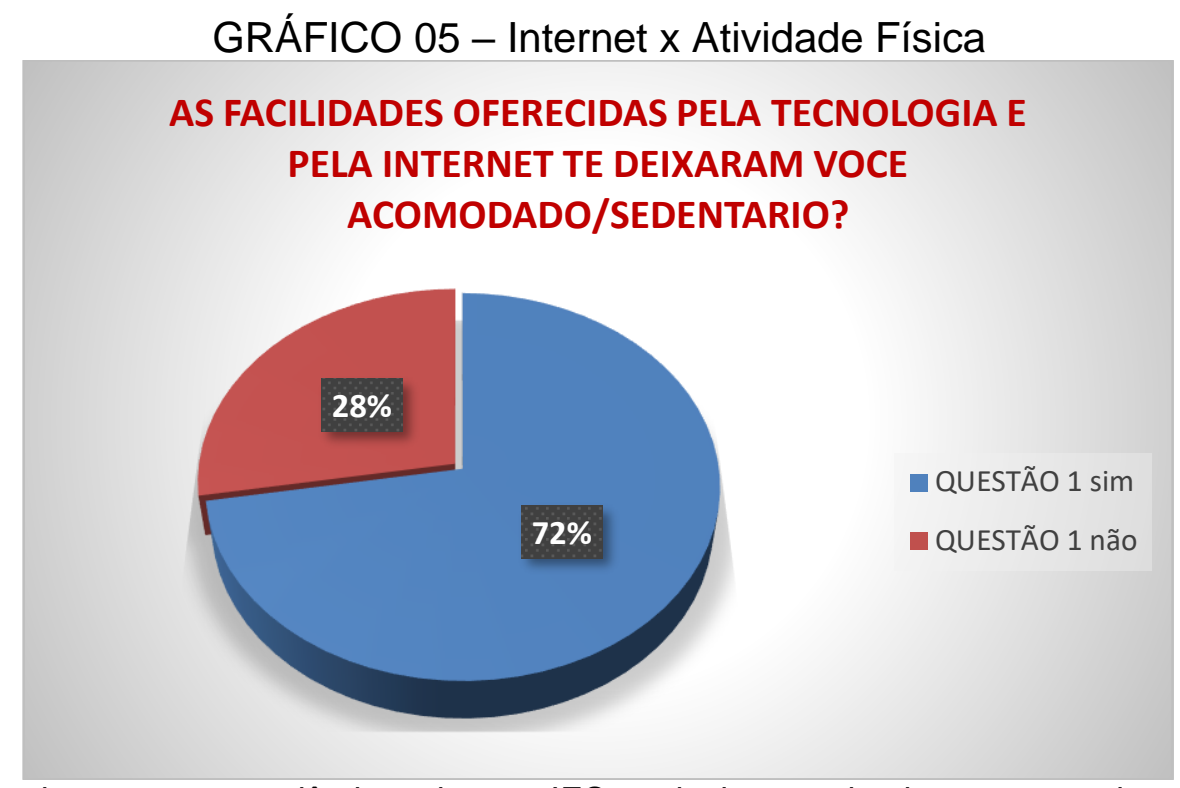

Fonte: Dados coletados entre os acadêmicos de uma IES particular no primeiro semestre do ano de 2019.

O uso de smartphones ocasiona mudanças de postura corporal, bem como a sobrecarga da cervical e da cabeça que estão sempre direcionadas a tela do aparelho, essa repetição de movimentos poderá acarretar sintomas como as dores musculoesqueléticas (GUSTAFSSON et. al., 2016).

De acordo com Pereira et al. (2013), as lesões musculoesqueléticas relacionadas com o uso do smartphone que incluem fadiga muscular devido aos movimentos repetidos do membro superior, essencialmente a flexão da cervical e a flexão do ombro, trazendo com isso, rigidez, alterações na sensibilidade na região cervical.

TABELA 01

\begin{tabular}{|c|c|c|c|c|}
\hline \multicolumn{5}{|c|}{ PROBLEMAS ADVINDOS DO MAL USO DO SMARTPHONE } \\
\hline & \multicolumn{2}{|c|}{ SIM } & \multicolumn{2}{|c|}{ NÃO } \\
\hline & (n) & $(\%)$ & $(n)$ & $(\%)$ \\
\hline Redução no Sono & 87 & $57 \%$ & 65 & $43 \%$ \\
\hline $\begin{array}{l}\text { Distúrbio com audição, visão e postura } \\
\text { após uso intenso. }\end{array}$ & 93 & $61 \%$ & 59 & $39 \%$ \\
\hline 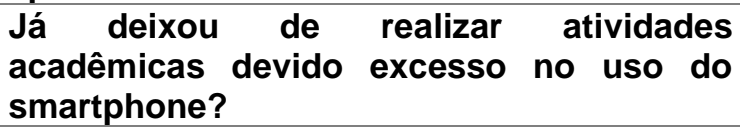 & 104 & $68 \%$ & 48 & $32 \%$ \\
\hline
\end{tabular}

Um dos problemas mais preocupantes no contexto, é o fato de quase de $70 \%$ do público acadêmico deixar de executar tarefas importantes a seu futuro profissional.

De acordo com Lemos (2016), A dependência da conectividade é observada em todas as faixas etárias e classes sociais. A rapidez no acesso e conexões ilimitadas, trouxeram a praticidade, facilitando o uso em qualquer hora e em qualquer lugar. 
Apesar das mídias digitais disponibilizarem vasta oportunidades de conhecimento e interação entre as pessoas, também estão sujeitas a experiências negativas, como o cyberbullying, que envolve o uso das mídias sociais para assediar, intimidar, ameaçar e prejudicar outras pessoas (HINDUJA; PATCHIN, 2010).

Contudo, a necessidade das pessoas de estarem conectadas favorece a um uso sem limites de smartphones causando o distanciamento social e familiar do usuário, que pode ser extremamente prejudicial ao convívio familiar.

Todo esse processo pode levar ainda a complicações emocionais, percebe-se que 72 (47\%) dos acadêmicos relata já ter sofrido algum tipo de agressão ou ofensa via internet e 81 acadêmicos (53\%) relatam já ter compartilhado algum tipo de boato ou mentira.

A tabela 02 apresenta a rotina de uso de celular no período noturno, observe abaixo:

TABELA 02 ROTINA NOTURNA DE USO DO SMARTPHONE

\begin{tabular}{|c|c|c|c|c|c|c|}
\hline & \multicolumn{2}{|c|}{ SIM } & \multicolumn{2}{|c|}{ NÃO } & \multicolumn{2}{|c|}{ NÃO RESPONDEU } \\
\hline & $(n)$ & $(\%)$ & (n) & $(\%)$ & (n) & $(\%)$ \\
\hline $\begin{array}{l}\text { Você desliga o aparelho } \\
\text { enquanto dorme? }\end{array}$ & 23 & $15 \%$ & 129 & $85 \%$ & 0 & $0 \%$ \\
\hline $\begin{array}{l}\text { Quando vai dormir o } \\
\text { aparelho fica próximo a } \\
\text { você? }\end{array}$ & 80 & $53 \%$ & 54 & $35 \%$ & 18 & $12 \%$ \\
\hline $\begin{array}{l}\text { Você se preocupa com } \\
\text { a radiação emitida pelo } \\
\text { aparelho? }\end{array}$ & 55 & $36 \%$ & 77 & $51 \%$ & 20 & $13 \%$ \\
\hline
\end{tabular}

Fonte: Dados coletados entre os acadêmicos de uma IES particular no primeiro semestre do ano de 2019.

Outro dado que chama a atenção é a conectividade, é alta até mesmo nos momentos de repouso, e a grande maioria, segundo a tabela acima, não desliga o celular, dorme com ele próximo ao corpo e ainda não se preocupa com radiações emitidas.

Para Pedroso e Bonfim (2017), O excesso de uso das mídias sociais tem sido a principal causa da falta de disciplina e limite, isso gera a inversão de valores, que leva a inúmeras consequências principalmente nas áreas comportamental, social, de aprendizado e ainda de identidade. 
Silva (2013), descreve que além da família os educadores também precisam ter um bom relacionamento com as tecnologias, pois estão lidando com uma geração digital e estão em busca de bons rendimentos.

Para Araújo (2018), os professores precisam criar estratégias para conciliar a atenção dos alunos com os aplicativos virtuais, desenvolvendo atividades nas redes mais usadas pelos alunos em sala de aula, como por exemplo, criar grupos fechados para cada turma, onde é possível sanar dúvidas e melhorar a comunicação entre alunos e professores.

De acordo com Bedi (2014) o papel do professor, vai além de prover novas informações, é preciso um contexto mais amplo, tendo em vista que o professor também possui um papel importante em ajudar os alunos no processo de abstração e diferenciação de informações importantes e confiáveis.

Enfim, a tecnologia em si, trouxe inestimáveis benefícios, contudo é preciso ter cautela para usa-la sem correr riscos e ter prejuízos, ninguém está totalmente protegido, todos poderão ser alvo e sofrer algum tipo de crime virtual, pais precisam estarem atentos a páginas acessadas pelos filhos, crianças também são expostas as intimidações virtuais, a vida virtual requer proteção, prudência e cuidado, assim como temos no nosso cotidiano (TOMÉ, 2018).

\section{CONSIDERACOEES FINAIS}

Observa-se que a discussão da temática em questão, apresentou uma evolução significativa nos últimos anos, é notório que a internet trouxe facilidades para o acesso à informação, no campo acadêmico as novas tecnologias facilitou a pesquisa e aumentou a quantidade de informação, melhorando o conhecimento de professores e alunos contudo ainda é observado uma resistência por parte de alguns professores que não estão aptos e são inseguros quanto ao uso de tecnologia e trabalho.

As informações anteriormente apresentadas mostram que dentre os 152 acadêmicos entrevistados a maioria tem entre 18 e 30 anos de idade, são do sexo feminino e cursam os períodos iniciais dos seus respectivos cursos, desta forma os resultados sugerem que a maioria possui acesso aos celulares inteligentes.

Percebe-se que este acesso prejudica, em diversas áreas do cotidiano acadêmico, já que apresenta utilização por períodos acima do necessário, mostrando equívocos no 
manuseio, sendo majoritariamente utilizado para acessos em aplicativos de chats de bate papo, o que acaba tirando o foco do aprendizado.

Vale ressaltar a necessidade em se discutir o uso e o controle, tanto a nível individual quanto social.

É preocupante o fato de muitos acadêmicos estarem compartilhando notícias falsas e ainda passarem por constrangimentos se incluírem em agressões online, podendo num futuro próximo, sujeito a adquirir problemas mentais diante desse cenário.

A pesquisa evidenciou distúrbios patológicos, onde a maioria dos estudantes passam por agravos posturais, perca de audição, alterações visuais, desenvolvendo distúrbios de sono, deixam de executar atividades acadêmicas... Comprometendo além de seu estado de saúde, seu aprendizado.

Portanto, a discussão sobre a temática conseguiu demonstrar possíveis alterações tanto estado de saúde, quando intelectual.

\section{REFERENCIAS}

Akin, A., Altundag, Y., Turan, M. E., \& Akin, U. (2014). The validity and reliability of the Turkish version of the smartphone addiction scale-short form for adolescent. Social and behavioral sciences. Disponivel em:

https://www.sciencedirect.com/science/article/pii/S1877042814052240. Acessado em: 25 ago. 2018, 15:25.

ARAUJO R.V. O uso de redes sociais como prática no ensino de história. São Paulo 2018. Disponível em: file:///C:/Users/eduar/Downloads/1721-3988-1-SM.pdf. Acessado em: $15 / 12 / 2018$ as $15: 00 h s$.

BARROS, B. M. C., RICHTER,. A Criança e o Adolescente Internauta - Doenças, Celeumas e Distúrbios: Uma análise Jurídica das Tecnologias da Informação e Comunicação sob a ótica do Princípio da Proteção Integral. Disponível em: http://publicadireito.com.br/artigos/?cod=8ce13ccd4a1b7b88. Acesso em: 11 set. 2018, $21: 15$.

BEDI, K. Tablet PC \& smartphone uses in education: INTERNATIONAL CONVENTION ON INFORMATION AND COMMUNICATION TECHNOLOGY, ELECTRONICS AND MICROELECTRONICS (MIPRO). Čakovec, Croácia 2014. Disponível em:<https://ieeexplore.ieee.org/abstract/document/6859703/>. Acessado em: 03/01/2019 as 08:23hs.

BOZZA T.C.L. O uso da tecnologia nos tempos atuais: análise de programas de intervenção escolar na prevenção e redução da agressão virtual. Campinas, SP 2016. Disponível em: 
http://repositorio.unicamp.br/bitstream/REPOSIP/305317/1/Bozza ThaisCristinaLeiteBozz a M.pdf. Acessão em: 21/07/2018 as 10:43hs.

CARVALHO TMCS, et al. Qualidade do Sono e Sonolência Diurna Entre Estudantes Universitários de Diferentes Áreas. Universidade Federal Rural de Pernambuco UFRPE, Recife-PE 2013. Disponível em:

http://www.revistaneurociencias.com.br/edicoes/2013/RN2103/original/854original.pdf. Acessado em: 02/11/2018 as 21/10hs.

Greenfield, D. (2011). As propriedades de dependência do uso de internet. Em Young, K. S. \& Abreu, C. N. Dependência de Internet: manual e guia de avaliação e tratamento. (pp.169-190). São Paulo: Artmed. Disponível em:

<https://www.dependenciadeinternet.com.br/nabucocap08.pdf >. Acessado em: 22 set. $2018,14: 42$.

GUSTAFSSON E, et al. Mensagens de texto sobre telefones celulares e distúrbios musculoesqueléticos em adultos jovens: um estudo de coorte de cinco anos, Gotemburgo-Suécia 2016. Disponível em:

https://www.sciencedirect.com/science/article/pii/S0003687016301235?via\%3Dihub. Acessado em: 03/01/2019 as 13:00hs.

International Data Corporation, Brasil (2015). Estudo da idc Brasil aponta que, em 2014, brasileiros compraram cerca de 104 smartphones por minuto. Disponível em: http://br.idclatin.com/releases/news.aspx?id=1801. Acessado em: 28 de ago.2018, 20:12.

KIM S.E, KIM J.W, JEE Y.S. Relação entre vício em smartphones e atividade física em estudantes internacionais chineses na Coréia. (2015). Disponível em:

$<$ https://www.ncbi.nlm.nih.gov/pmc/articles/PMC4627682/>. Acessado em: 02/10/1018 as 18:10.

KLAUER, S. G. et al.(2014). Distracted driving and risk of road crashes among novice and experienced drivers. New England Journal of Medicine. Disponivel em:

$<$ https://www.nejm.org/doi/full/10.1056/NEJMsa1204142>. Acessado em: 12 set. 2018, 08:30.

KOBS, Fabio Fernando. Os possíveis efeitos do uso dos dispositivos móveis por adolescentes: análise de atores de uma escola pública e uma privada. 2017.

Disponível em:

<http://repositorio.utfpr.edu.br/jspui/bitstream/1/2768/1/CT_PPGTE_D_Kobs\%2C\%20Fabi o\%20Fernando_2017.pdf>. Acessado em: 26/09/2018, as 17:45hs.

Kwon, M., Lee, J. Y., Won, W. Y. et al. (2013). Development and validation of a smartphon addiction scale (sas). Disponvel em:

https://journals.plos.org/plosone/article?id=10.1371/journal.pone.0056936. Acessado em: 08 set. $2018,14: 25$.

LEMOS, I. L. et al. Baralhos das Dependências Tecnológicas: Controlando o uso de jogos eletrônicos, internet e aparelho celular. Novo Hamburgo: Editora Sinopsys 2016, 48p .Disponivel em:

<https://www.sinopsyseditora.com.br/upload/produtos pdf/409.pdf>. Acessado em:

03/06/2018 as 13:45hs. 
LIMA M, PEREIRA J.C, Uso de dispositivos móveis na medicina. Paranavai-PR (2015). Disponível em:

<http://web.unipar.br/ seinpar/2015/ include/artigos/Marcos Araujo Lima.pdf>. Acessado em: 15/08/2018 as 22:18hs.

MELO D.G.S. et al. Dependência tecnológica: A doença da contemporaneidade no contexto familiar, Olinda- Pe - Brasil, 2018. Disponível em:

$<$ http://www.psicologia.pt/artigos/textos/A1276.pdf >. Acessado em: 15/11/2018 as 20:00hs.

MINISTERIO DA SAUDE, Aplicativo do SUS aproxima cidadãos dos serviços públicos de saúde 18 de Setembro de 2018. Disponível em:

<http://portalms.saude.gov.br/noticias/agencia-saude/44394-aplicativo-do-sus-aproximacidadaos-dos-servicos-publicos-de-saude $>$. Acessado em: 26/09/2018 as 20:00hs.

PEDROSO C.M.S., BOMFIM E.L.S. Impacto da tecnologia no ambiente familiar e suas consequências na escola E-FACEQ: Revista dos Discentes da Faculdade Eça de Queirós, ISSN 2238-8605, Ano 6, Número 10, Jandira-Sp 2017. Disponível em: http://uniesp.edu.br/sites/ biblioteca/revistas/20171030115836.pdf. Acessado em: 18/01/2019 as 20:25hs.

PEREIRA et al. Segurando um computador tablet com uma mão: efeito dos recursos de design do tablet em biomecânica e usabilidade subjetiva entre usuários com mãos pequenas. Berkeley, CA, EUA 2013. Disponível em:

$<$ https://www.researchgate.net/publication/255175070 Holding a tablet computer with o ne hand Effect of tablet design features on biomechanics and subjective usability a mong users with small hands $>$. Acessado em: 02/01/2019, as 13:42hs.

REZENDE, L.C.M., et al. Tecnologia móvel para registros da avaliação clínica de recém-nascidos (2016). Disponivel em:

$<$ http://www.saude.ufpr.br/portal/revistacogitare/wpcontent/uploads/sites/28/2016/10/4286 8-173637-1-PB.pdf $>$. Acessado em: 13/08/2018 as 14:05hs.

ROCHA, L.F. Avaliação de riscos biomecânicos na saúde ocupacional por meio de imagens infravermelhas. Curitiba-PR 2018. Disponivel em:

<http://repositorio.utfpr.edu.br/jspui/bitstream/1/3312/1/CT PPGEB M Rocha\%2C\%20Lie ge\%20da\%20Fonseca 2018.pdf>. Acessado em: 13/12/1018, as 09:34hs.

SILVA, F. M. S. M., LOPES, B. J., \& LIMA, C. F. (2017). Adaptação da escala de uso compulsivo de Internet para avaliar dependência de smartphone. Disponível em em: <http://www.scielo.org.co/pdf/apl/v36n1/1794-4724-apl-36-01-00155.pdf>. Acessado em: 22 est. 2018, 22:05.

SILVA, L. M.; SILVA, M. F.; MORAES, D. C. A Internet como ferramenta tecnológica e as consequências de seu uso: Aspectos positivos e negativos. 2013. Gurupi-TO, 2013. Disponível em:

<https://semanaacademica.org.br/system/files/artigos/artigo_sobre_internet_corrigido_0.p df >acessado em: 14/08/2018 às 20:23hs.

SILVA, P. K. L. A escola na era digital. In: ABREU, Cristiano Nabuco de;

EISENSTEIN, Evelyn; ESTEFENON, Susana Graciela Bruno. Vivendo esse mundo 
digital: impactos na saúde, na educação e nos comportamentos sociais. Porto Alegre, 2013. p. 137-145. Disponivel em:

https://books.google.com.br/books?hl=ptBR\&lr=\&id=who7AgAAQBAJ\&oi=fnd\&pg=PT2\&d $\mathrm{q}=$ SILVA,+Patricia+Konder+Lins.+A+escola+na+era+digital.+In:+ABREU,+Cristiano+Nabu co+de\%3B+EISENSTEIN,+Evelyn\%3B+ESTEFENON,+Susana+Graciela+Bruno.+Vivend o+esse+mundo+digital:+impactos+na+sa\%C3\%BAde, + na +educa $\% \mathrm{C} 3 \% \mathrm{~A} 7 \% \mathrm{C} 3 \% \mathrm{~A} 30+\mathrm{e}+$ nos+comportamentos+sociais.+Porto+Alegre:+Artmed, $+20 \&$ ots $=3 \mathrm{MdSsluTeX \& sig=S63eB}$ iCmCPhoAlm6UoUzp2IvmG4\#v=onepage\&q\&f=false. Acessado em: 25/02/2019 as 20:45

TOMÉ P.S. O uso da internet e novas tecnologias numa sociedade conectada: possibilidades, desafios, perigos à luz da ética. São Leopoldo (2018). Disponível em: http://dspace.est.edu.br:8080/jspui/bitstream/BRSIFE/844/1/tom\%C3\%A9 ps tmp551.pdf. Acessado em: 03/03/2019 as $14: 45$ hs

Vega, L. E. F., Correa, G. B., \& Sánchez, D. C. (2015). Contribuición de la mercadotecnia em la utilización del smartphone para videojuegos, convirtiéndola em uma posible adicción em los jóvenes. European scientific jounal, 11(8), 3545. Disponível em: http://eujournal.org/index. php/esj/article/view/5253/5064. Acessado em: 25 de ago. 2018, 09:30. 